\title{
PENGARUH LAYANAN AKADEMIK TERHADAP KEPUASAN MAHASISWA PROGRAM PASCASARJANA UNIVERSITAS TERBUKA PADA UNIT PROGRAM BELAJAR JARAK JAUH (UPBJJ) MATARAM
}

\author{
Hery Susanto (herys@ut.ac.id) \\ Universitas Terbuka Unit Program Belajar Jarak Jauh Mataram
}

\begin{abstract}
This research is aimed at analyzing the influence of academic service quality to the satisfaction of Master Degree Program (PPS) - Open University (UT) in the distance study unit program (UPBJJ) Mataram. The data were subsequently analyzed by double linear regression. This research finding showed that, partially the indicator of reliability dimension, responsiveness, and assurance were not influenced significantly by the students' satisfaction. It was caused by the Master Degree Program - UT in UPBJJ Mataram has not provided a service that is expected by the students. Otherwise the indicator of tangibles and empathy partially have significant role that influences the students' satisfaction. From the five indicators, it can be seen that the empathy dimension has dominant role that influences the satisfaction of students in Master Degree Program - UT in UPBJJ Mataram. Simultaneously, the quality of academic service consisted of tangible, reliability, responsiveness, assurance and empathy that has highly significant role. The higher of service quality increased the higher of students' satisfaction level in Master Degree Program - UT in UPBJJ Mataram.
\end{abstract}

Keywords: academic service quality, students' satisfaction, UPBJJ Mataram

\begin{abstract}
ABSTRAK
Penelitian ini bertujuan menganalisis pengaruh kualitas layanan akademik terhadap kepuasan mahasiswa Program Pascasarjana (PPs) Universitas Terbuka pada Unit Program Belajar Jarak Jauh (UPBJJ) Mataram. Teknik analisis data dengan menggunakan regresi linier berganda. Hasil penelitian menunjukkan bahwa, secara parsial indikator dimensi keterandalan (reliability), responsiveness dan assurance tidak berpengaruh secara signifikan terhadap kepuasan mahasiswa, hal ini disebabkan PPs-UT pada UPBJJ Mataram belum memberikan pelayanan seperti yang diharapkan oleh mahasiswa. Selanjutnya, pada indikator tangibles dan empathy secara parsial memiliki pengaruh yang signifikan terhadap kepuasan mahasiswa. Dari ke lima indikator tersebut, dimensi emphaty memiliki pengaruh yang paling dominan terhadap kepuasan mahasiswa Program Pascasarjana UT pada UPBJJ Mataram. Secara simultan, kualitas layanan akademik yang terdiri dari tangible, reliability, responsiveness, assurance, dan empathy mempunyai pengaruh signifikan yang sangat tinggi, artinya semakin tinggi kualitas pelayanan maka semakin tinggi pula tingkat kepuasan mahasiswa PPs-UT pada UPBJJ Mataram.
\end{abstract}

Kata Kunci: kualitas layanan akademik, kepuasan mahasiswa, UPBJJ Mataram 
Pendidikan tinggi yang menerapkan Sistem Belajar Jarak Jauh mensinyalir bahwa layanan akademik dan non-akademik merupakan faktor penting yang menunjang keberhasilan belajar mahasiswa mereka. Holtzclaw (1986) juga menyatakan bahwa mahasiswa program jarak jauh khususnya yang mengambil program sarjana memerlukan layanan akademik. Sementara itu, William dan William (1987) menyatakan bahwa pendidikan jarak jauh (PJJ) dikenal sebagai pendidikan yang memerlukan layanan akademik bagi mahasiswanya melebihi dari apa yang diberikan oleh dosen konvensional dengan segala bahan mengajarnya.

Keberhasilan Universitas Terbuka (UT) sebagai salah satu perguruan tinggi sangat ditentukan oleh kualitas pelayanan yang diberikan, dimana pelayanan akademik yang berkualitas dapat diidentifikasi melalui kepuasan pelanggan yang dalam hal ini adalah mahasiswa. Cravens (Handayani, et al., 2003) menyatakan bahwa untuk mencapai tingkat kepuasan yang tinggi, diperlukan adanya pemahaman tentang apa yang diinginkan oleh konsumen yang ada dalam lembaga untuk memenuhi kebutuhan konsumen yang bersangkutan. Hal ini mengindikasikan bahwa kepuasaan mahasiswa berawal dari pemahaman tentang apa yang yang diinginkan oleh mahasiswa. Salah satu hal yang sangat diperlukan oleh mahasiswa adalah pelayanan yang baik, mulai dari proses registrasi, perkuliahan, ujian sampai dengan mahasiswa menyelesaikan kuliah. Untuk menunjang hal tersebut, diperlukan perencanaan yang matang, fasilitas yang memadai, dan sumber daya manusia yang mendukung.

PPs-UT sebagai institusi penyedia layanan pendidikan tinggi, harus senantiasa mengutamakan kepuasan mahasiswa sebagai pelanggan dengan memberikan pelayanan terbaik. Beberapa bidang pelayanan yang harus dikembangkan secara berkelanjutan meliputi: kurikulum program studi, proses pembelajaran, sumber daya manusia (dosen, pegawai, dan teknisi), mahasiswa, sarana dan prasarana, suasana akademik, penelitian serta publikasi, pengabdian kepada masyarakat, manajemen lembaga, sistem informasi, dan kerjasama dalam/luar negeri. Pelayanan akademik yang baik dapat membentuk citra positif bagi UT sebagai salah satu perguruan tinggi negeri terkemuka penyedia layanan program pascasarjana. Pada aktivitas layanan akademik yang diberikan tersebut terdapat kemungkinan mahasiswa merasa kurang puas dengan adanya atribut layanan yang dianggap tidak optimal sehingga perlu dilakukan penelitian untuk menganalisis kualitas layanan akademik yang diberikan khususnya di UPBJJ Mataram terhadap kepuasan mahasiswa PPs UT.

Tabel 1. Penerimaan Mahasiswa Baru Program PPs-UT UPBJJ Mataram per Masa Registrasi (masa registrasi 2009.2 sampai dengan masa registrasi 2012.1)

\begin{tabular}{cccccc}
\hline \multirow{2}{*}{ PRODI } & \multicolumn{5}{c}{ Tahun Akademik / Semester } \\
\cline { 2 - 6 } & 2009.2 & 2010.1 & 2010.2 & 2011.1 & 2011.2 \\
\hline MAP & 20 & 18 & 0 & 34 & 39 \\
MM & 20 & 0 & 26 & 0 & 20 \\
MPMT & 0 & 0 & 0 & 15 & 31 \\
\hline
\end{tabular}

Sumber : UPBJJ-UT Mataram

\section{Kualitas Pelayanan}

Konsep kualitas pelayanan dapat dipahami melalui perilaku konsumen (Consumer Behavior), yaitu suatu perilaku yang dimainkan oleh konsumen dalam mencari, membeli, menggunakan, dan mengevaluasi suatu produk maupun pelayanan yang diharapkan dapat memuaskan kebutuhan 
mereka. Zeithaml et al. (1990:20), menyatakan bahwa: kualitas pelayanan ditentukan oleh dua hal, yaitu Expected service dan preceived service. Expected service dan Perceived service ditentukan oleh Dimention of service quality yang terdiri dari sepuluh dimensi, yaitu:

1. tangible (terjamah),

2. reliability (handal),

3. responsiveness (tanggap),

4. competence (kompeten),

5. courtesy (ramah),

6. credibility (dapat dipercaya),

7. security (aman),

8. access (akses),

9. communication (komunikasi),

10. understanding the customer (memahami pelanggan).

Zeithaml et al. (1990:26), menyederhanakan sepuluh menjadi lima dimensi yang dinyatakan dengan SERVQUAL dimensions, yaitu:

1. Tangibles (kualitas pelayanan yang berupa sarana fisik perkantoran, komputerisasi administrasi, ruang tunggu, tempat informasi, dan sebagainya);

2. Reliability (kemampuan dan keandalan untuk menyediakan pelayanan yang terpercaya);

3. Responsiveness (kesanggupan untuk membantu dan menyediakan pelayanan secara cepat dan tepat, serta tanggap terhadap keinginan konsumen);

4. Assurance (kemampuan dan keramahan, serta sopan santun pegawai dalam meyakinkan kepercayaan konsumen);

5. Emphaty (sikap tegas tetapi penuh perhatian dari pegawai terhadap konsumen)

\section{Keputusan Menteri PAN Nomor: 63/KEP/M.PAN/7/2003 Tentang Prinsip Pelayanan}

Berdasarkan prinsip pelayanan sebagaimana telah ditetapkan dalam Keputusan Menteri PAN Nomor: 63/KEP/M.PAN/7/2003, yang kemudian dikembangkan menjadi 14 unsur yang "relevan", "valid" dan "reliabel", sebagai unsur minimal yang harus ada untuk dasar pengukuran Indeks Kepuasan Masyarakat (IKM), adalah sebagai berikut:

1. Prosedur pelayanan

2. Persyaratan Pelayanan

3. Kejelasan petugas pelayanan

4. Kedisiplinan petugas pelayanan

5. Tanggung jawab petugas pelayanan

6. Kemampuan petugas pelayanan

7. Kecepatan pelayanan

8. Keadilan mendapatkan pelayanan

9. Kesopanan dan keramahan petugas

10. Kewajaran biaya pelayanan

11. Kepastian biaya pelayanan

12. Kepastian jadwal pelayanan

13. Kenyamanan lingkungan

14. Keamanan Pelayanan 


\section{Kualitas Layanan Akademik}

Pengertian layanan akademik dalam kurikulum pembelajaran menurut (Rosita et al., 2011:3) adalah upaya sistematis pendidikan untuk memfasilitasi peserta didik menguasai isi kurikulum melalui proses pembelajaran sehingga mereka mampu mencapai kompetensi standar yang diterapkan. Kualitas pelayanan akademik merupakan perbandingan antara pelayanan akademik yang dirasakan pelanggan atau stakeholders dengan kualitas pelayanan akademik yang diharapkan pelanggan atau stakeholders (Pakpahan, 2004:47). Apabila kualitas layanan akademik yang dirasakan sama atau melebihi kualitas pelayanan yang diharapkan maka pelayanan dikatakan berkualitas.

\section{Kepuasan Mahasiswa}

Kepuasan adalah sesuatu yang bersifat individual. Setiap individu memiliki tingkat kepuasan yang berbeda-beda sesuai dengan sistem nilai yag berlaku (Rivai, 2004). Semakin tinggi penilaian terhadap kegiatan yang dirasakan sesuai dengan keinginan individu, maka semakin tinggi kepuasan terhadap kegiatan tersebut. Dengan demikian dapat dikatakan bahwa kepuasan merupakan evaluasi yang menggambarkan seseorang atas perasaan sikap senang atau tidak senang dalam beraktivitas.

Kepuasan pelanggan merupakan tingkat perasaan di mana seseorang menyatakan hasil perbandingan atas kinerja produk atau jasa yang diterima dan yang diharapkan (Kotler, 2000). Seseorang dengan tingkat kepuasan yang tinggi, mengindikasikan sikap positif. Sebaliknya seseorang yang tidak puas dengan pekerjaannya mengindikasikan sikap yang negatif. Selanjutnya, kepuasan kerja meliputi indikator-indikator sebagai berikut: 1) Pekerjaan itu sendiri, 2) Kesesuaian pekerjaan dengan kepribadian, 3) Upah dan promosi, 4) Sikap teman sekerja dan atasan, dan 5) Kondisi lingkungan kerja.

Sementara itu, apabila ditinjau lebih lanjut, pencapaian kepuasan pelanggan melalui kualitas pelayanan dapat ditingkatkan dengan beberapa pendekatan sebagai berikut:

1. Memperkecil kesenjangan-kesenjangan yang terjadi antara pihak manajemen dan pelanggan. Demikian juga penelitian dengan metode pengamatan bagi pegawai perusahaan tentang pelaksanaan pelayanan.

2. Perusahaan harus mampu membangun komitmen bersama untuk menciptakan visi di dalam perbaikan proses pelayanan.

3. Memberi kesempatan kepada pelanggan untuk menyampaikan keluhan. Dengan membentuk sistem saran dan kritik, misalnya dengan hotline bebas pulsa.

4. Mengembangkan dan menerapkan accountable, proactive, dan partnership marketing sesuai dengan situasi pemasaran.

\section{Hubungan Kualitas Layanan Akademik Dengan Kepuasan Mahasiswa}

Taylor (Semiawan, 1998) menyatakan bahwa kualitas pendidikan tinggi harus didasarkan pada empat pilar pokok sumber daya di bidang pendidikan tinggi, yaitu sumber daya fisik (physical resources), keuangan (financial resources), informasi (information resources), dan sumber daya manusia (human resources). Konsep kualitas pelayanan yang sangat popular adalah konsep ServQual yang dikembangkan oleh Parasuraman, Berry dan Zeithaml sejak 15 tahun yang lalu. Pertama kali konsep dari dimensi kualitas pelayanan diformulasikan menjadi sepuluh dimensi, kemudian disederhanakan menjadi lima dimensi (Irawan, 2002).

Kotler (2000) mengungkapkan lima faktor yang menentukan kualitas pelayanan jasa meliputi: 1) tangible (bukti langsung) mencakup fasilitas fisik, perlengkapan, pegawai, dan sarana komunikasi; 
2) reliability (reliabilitas), yaitu kemampuan memberikan pelayanan yang dijanjikan dengan segera, akurat, dan memuaskan; 3) responsiveness (daya tanggap), yaitu keinginan staf membantu para pelanggan dan memberikan layanan dengan tanggap; 4) assurance (jaminan), mencakup pengetahuan, kompetensi, kesopanan, dan sifat dapat dipercaya yang dimiliki staf, bebas dari bahaya, resiko, atau keragu-raguan; (5) empathy (empati), meliputi kemudahan dalam menjalin relasi, komunikasi yang baik, perhatian pribadi, dan pemahaman atas kebutuhan individu para pelanggan.

Kartono (1987) menyatakan bahwa uang tidak selamanya menjadi motif primer bagi seseorang, tetapi kebanggaan dan minat yang besar terhadap sesuatu akan memberi kepuasan tersendiri. Kepuasan juga dapat dipandang sebagai suatu perbandingan apa yang dibutuhkan dengan apa yang diperoleh. Seseorang akan terpenuhi kepuasannya jika perbandingan tersebut cukup adil.

Menurut Day Tse dan Wilton dalam Tjiptono (1998), kepuasan pelanggan merupakan respon pelanggan terhadap evaluasi ketidaksesuaian yang dirasakan antara harapan tentang kinerja dengan kinerja aktual produk yang dirasakan setelah pemakaiannya tentang apa yang dibutuhkan seseorang.

Ada empat hal yang harus diperhatikan dalam peningkatan pembelajaran di perguruan tinggi (Sudarwan, 1995), meliputi: 1) metode mengajar; 2) mutu pembelajaran; 3) tidak hanya bersifat descriptive oriented tetapi mencakup penerapan ilmu yang dipelajari; dan 4) kegiatan pembelajaran membentuk mahasiswa untuk dapat berdiri sendiri secara akademis melalui pola pikir analitis.

\section{HASIL DAN PEMBAHASAN}

Gambaran responden dalam penelitian ini, dapat dilihat berdasarkan kuesioner yang telah diisi oleh mahasiswa Universitas Terbuka khususnya Program Pascasarjana (PPs) Mataram.

Tabel 2. Pembagian Distribusi Sampel (Penomoran Tabel)

\begin{tabular}{lccc}
\hline \multicolumn{1}{c}{$\begin{array}{c}\text { Program Pascasarjana UT } \\
\text { UPBJJ Mataram }\end{array}$} & Semester & Populasi & Sampel \\
\hline Mahasiswa Program MAP & III (tiga) & 22 & 9 \\
Mahasiswa Program MAP & IV (empat) & 24 & 11 \\
\hline Jumlah MAP & & 46 & 20 \\
\hline Mahasiswa Program MPMT & III (tiga) & 30 & 13 \\
Mahasiswa Program MPMT & IV (empat) & 13 & 5 \\
\hline Jumlah MPMT & & 43 & 18 \\
\hline Mahasiswa Program MM & III (tiga) & 18 & 8 \\
Mahasiswa Program MM & IV (empat) & 21 & 10 \\
\hline \multicolumn{1}{c}{ Jumlah MM } & 39 & 18 \\
\hline Jumlah Keseluruhan & & 128 & 56 \\
\hline
\end{tabular}

Sumber: UPBJJ-UT Mataram, 2011

Kuesioner disebar pada seluruh mahasiswa pada program studi MM, MAP, dan MPMT. Pengisian kuesioner oleh responden membutuhkan waktu antara 1 (satu) sampai 2 (dua) minggu. 
Jumlah kuesioner yang dikirim ke responden disesuaikan dengan jumlah sampel yang diuraikan sebelumnya pada bagian metodologi penelitian, yaitu sebanyak 56 mahasiswa. Pembagian distribusi sampel ditunjukkan pada Tabel 2.

Dari jumlah tersebut ternyata yang kembali hanya 47 responden, sedangkan kuesioner yang tidak kembali sebanyak 9 buah kuesioner. Dengan demikian maka tingkat pengembalian kuesioner (response rate) dalam penelitian ini adalah sebesar 83,93\% (47/56 x 100\%). Dengan demikian kuesioner yang dapat diolah sebanyak 47 kuesioner. Untuk lebih jelasnya perhitungan tingkat pengembalian kuesioner dapat dilihat pada Tabel 3.

Tabel 3. Penyebaran dan Tingkat Pengembalian Kuesioner

\begin{tabular}{lc}
\hline \multicolumn{1}{c}{ Keterangan } & $\Sigma$ Kuesioner \\
\hline Kuesioner yang dikirim ke responden & 56 \\
Kuesioner yang tidak dikembalikan & 9 \\
Kuesioner yang kembali & 47 \\
Kuesioner yang diolah & 47 \\
Response Rate $(47 / 56 \times 100 \%)$ & $83,93 \%$ \\
\hline
\end{tabular}

Sumber: Data Primer (diolah, 2012)

\section{Uji Asumsi Klasik}

\section{a. Uji Normalitas}

Hasil uji normalitas menunjukkan bahwa data terdistribusi normal, dengan melihat nilai Kolmogrof Smirnov dan masing-masing variabel tidak signifikan pada 0,05, karena probability lebih besar dari 0,05.

Tabel 4. Uji Normalitas Dat (One Sample Kolmogorow - Smirnow Test)

\begin{tabular}{llc}
\hline \multicolumn{1}{c}{ Keterangan } & Unstandardized Residual \\
\hline $\mathrm{N}$ & & 47,00 \\
Normal Parameters ${ }^{\mathrm{a}, \mathrm{b}}$ & Mean & 32,40 \\
& Std. Deviation & 3,327 \\
Most Extreme Differences & Absolute & 0,152 \\
& Positive & 0,152 \\
& Negative & $-0,086$ \\
Kolmogorov-Smirnov Z & & 1,045 \\
Asymp. Sig. (2-tailed) & & 0,225 \\
\hline Sumber: Data Primer Diolah (2012) & &
\end{tabular}

Berdasarkan Tabel 4 dapat dilihat bahwa nilai Kolmogorow Smirnov sebesar 1,045 dengan signifikansi pada 0,225 , maka dapat disimpulkan bahwa data berasal dari populasi yang berdistribusi normal.

\section{b. Uji Multikolinearitas}

Berdasarkan hasil uji multikolinearitas menunjukkan bahwa penelitian ini tidak mengandung Multikolinearitas, karena nilai VIF-nya dibawah 0,10 (VIF > 0,10). 
Tabel 5. Pengujian Multikolinearitas

\begin{tabular}{lc}
\hline \multicolumn{1}{c}{ Keterangan } & VIF \\
\hline Tangible & 1,827 \\
Reliability & 3,849 \\
Responsiveness & 2,411 \\
Assurance & 3,158 \\
Empathy & 3,245 \\
\hline Sumber: Data Primer Diolah (2012) &
\end{tabular}

Berdasarkan Tabel 5 dapat disimpulkan bahwa kelima variabel independen tersebut tidak terjadi multikolinieritas, karena nilai VIF-nya dibawah 0,10.

\section{c. Uji Heterokedastisitas}

Pengujian heteroskesdatisitas dalam penelitian ini dilakukan dengan uji Gleijser dan dalam uji ini variabel dikatakan tidak terjadi heteroskesdatisitas jika nilai probabilitas/signifikansi >0,05. Dengan demikian hasil Pengujian heteroskesdatisitas dalam penelitian ini dapat ditunjukkan pada Tabel 6 .

Tabel 6. Pengujian Heterokedastisitas

\begin{tabular}{lcc}
\hline \multicolumn{1}{c}{ Keterangan } & $\begin{array}{c}\text { Probabilitas / } \\
\text { Signifikansi }\end{array}$ & Keterangan \\
\hline Tangible & 0,212 & Tidak ada heterokedastisitas \\
Reliability & 0,671 & Tidak ada heterokedastisitas \\
Responsiveness & 0,273 & Tidak ada heterokedastisitas \\
Assurance & 0,296 & Tidak ada heterokedastisitas \\
Empathy & 0,718 & Tidak ada heterokedastisitas \\
\hline
\end{tabular}

Sumber: Data Primer Diolah (2012)

\section{d. Analisis Regresi dan Pengujian Hipotesis}

Pada analisis regresi linier berganda ini akan dilakukan uji secara parsial (uji t) dan simultan (uji F). Untuk lebih jelasnya dapat dilihat pada Tabel 7.

Tabel 7. Rekapitulasi Hasil Analisis Regresi Linier Berganda

\begin{tabular}{lccc}
\hline Keterangan & $\begin{array}{c}\text { Ustandardized } \\
\text { Coefficients }(\beta)\end{array}$ & T & $\begin{array}{c}\text { Probabilitas/ } \\
\text { Signifikansi }\end{array}$ \\
\hline Tangible & 0,258 & 1,861 & 0,040 \\
Reliability & $-0,006$ & $-0,048$ & 0,062 \\
Responsiveness & $-0,245$ & $-0,563$ & 0,576 \\
Assurance & 0,332 & 0,602 & 0,550 \\
Empathy & 1,216 & 1,526 & 0,036 \\
\hline
\end{tabular}

Sumber: Data Primer diolah (2012)

\section{e. Pengujian secara Parsial (Uji t)}

Berdasarkan hasil pengujian secara parsial (uji t) terhadap masing-masing variabel bebas dapat diketahui sebagai berikut: 
1. Hasil analisis regresi tangible (daya tanggap) terhadap kepuasan mahasiswa pada Tabel 6 menunjukkan nilai $0,040<a(0,05)$. Hal ini berarti secara parsial ada pengaruh yang signifikan dari tangible (daya tanggap) terhadap kepuasan mahasiswa.

2. Hasil analisis regresi reliability (keandalan) terhadap kepuasan mahasiswa pada Tabel 6 menunjukkan nilai $0,062>a(0,05)$. Hal ini berarti secara parsial tidak ada pengaruh yang signifikan dari reliability (keandalan) terhadap kepuasan mahasiswa.

3. Hasil analisis regresi responsiveness terhadap kepuasan mahasiswa pada Tabel 6 menunjukkan nilai $0,576>a(0,05)$. Hal ini berarti secara parsial tidak ada pengaruh yang signifikan dari responsiveness terhadap kepuasan mahasiswa.

4. Hasil analisis regresi assurance (jaminan) terhadap kepuasan mahasiswa pada Tabel 6. menunjukkan nilai 0,550 $>a(0,05)$. Hal ini berarti secara parsial tidak ada pengaruh yang signifikan dari assurance (jaminan) terhadap kepuasan mahasiswa.

5. Hasil analisis regresi emphaty terhadap kepuasan mahasiswapada Tabel 6 menunjukkan nilai $0,036<a(0,05)$. Hal ini berarti secara parsial ada pengaruh yang signifikan dari emphaty terhadap kepuasan mahasiswa.

Dengan demikian hasil analisis regresi parsial variabel bebas terhadap variabel terikat pada Tabel 7 dapat disimpulkan bahwa variabal kualitas layanan akademik (tangible dan empathy) secara parsial mempunyai pengaruh yang signifikan terhadap kepuasan mahasiswa (Y) pada Program Pascasarjana Universitas Terbuka pada Unit Program Belajar Jarak Jauh (UPBJJ) Mataram. Sementara itu, variabel kualitas layanan akademik (reliability, responsiveness, dan assurance) secara parsial tidak mempunyai pengaruh yang signifikan terhadap kepuasan mahasiswa (Y) pada Program Pascasarjana Universitas Terbuka pada Unit Program Belajar Jarak Jauh (UPBJJ) Mataram.

Sementara itu, variabel kualitas layanan akademik (emphaty) mempunyai koefisien determinasi parsial paling besar dari variabel lainnya. Jadi dapat disimpulkan bahwa variabel kualitas layanan akademik (emphaty) mempunyai pengaruh paling dominan terhadap kepuasan mahasiswa (Y). Pengaruh kualitas layanan akademik (emphaty) yang dominan ini didukung oleh adanya data hasil penelitian di lapangan bahwa terjadi korelasi yang paling kuat dengan kepuasan mahasiswa Program Pascasarjana Universitas Terbuka pada Unit Program Belajar Jarak Jauh (UPBJJ) Mataram sebesar 1.216 (nilai koefisien regresi $\beta$ ).

\section{f. Pengujian secara Simultan (Uji F)}

Berdasarkan hasil uji secara simultan pada tabel Tabel 6 menunjukkan bahwa nilai $F$ hitung adalah sebesar 4.868 dengan nilai probabilitas sebesar $0,001(p<0,05)$ sehingga Ho ditolak. Hal ini berarti variabel kualitas layanan akademik (tangible, reliability, responsiveness, assurance, dan empathy) secara simultan mempunyai pengaruh yang signifikan terhadap kepuasan mahasiswa (Y) pada Program Pascasarjana Universitas Terbuka pada Unit Program Belajar Jarak Jauh (UPBJJ) Mataram. Dengan demikian hipotesis dapat diterima.

\section{g. Pengujian Koefisien Determinasi}

Berdasarkan hasil pengujian koefisien determinasi pada Tabel 6. menunjukkan bahwa nilai $\mathrm{R}^{2}$ sebesar 0,373. Hal ini berarti sebesar 37,3\% tingkat kepuasan mahasiswa dapat dijelaskan oleh variabel kualitas layanan akademik (tangible, reliability, responsiveness, assurance, dan empathy), sedangkan sisanya sebesar $62,7 \%$ (100\%-37,3\%) dipengaruhi oleh variabel lain diluar model. Variabel lain dalam penelitian ini adalah tentang sistem perkuliahan jarak jauh dengan waktu tatap 
muka yang terbatas, durasi perkuliahan atau TTM yang terbatas, dan fasilitas ruangan perkuliahan sebagian masih ada yang kurang memadai. Hasil penelitian ini, didukung oleh temuan Ndendo (2007) dan Effiyaldi (2008) bahwa mahasiswa masih belum merasa puas akan pelayanan yang diberikan oleh lembaga perguruan tinggi terutama yang berhubungan dengan kualitas, keterbatasan waktu, fasilitas ruangan, dan SDM.

Berdasarkan hasil analisis di atas, maka dapat disusun persamaan regresi sebagai berikut:

$Y=16,287+0,258 X_{1}-0,006 X_{2}-0,245 X_{3}+0,332 X_{4}+1,216 X_{5}+e$

Keterangan:

$Y=$ Variabel terikat (Kepuasan Mahasiswa)

$\mathrm{X}_{1}=$ Tangible (daya tanggap)

$\mathrm{X}_{2}=$ Reliability (Keandalan)

$\mathrm{X}_{3}=$ Responsiveness

$\mathrm{X}_{4}=$ Assurance

$\mathrm{X}_{5}=$ Empathy

Hasil dari penelitian ini dapat diketahui bahwa tanggapan mahasiswa tentang kualitas layanan akademik Program Pascasarjana Universitas Terbuka pada Unit Program Belajar Jarak Jauh (UPBJJ) Mataram yang terdiri dari indikator tangible, reliability, responsiveness, assurance, dan empathy mempengaruhi kepuasan mahasiswa dengan dibuktikan melalui nilai $\mathrm{F}$ hitung sebesar 4.868 dan nilai probabilitas sebesar $0,001(p<0,05)$ sehingga Ho ditolak dan Ha diterima. Hal tersebut menunjukkan pengaruh yang signifikan secara serentak (simultan) dari tangible, reliability, responsiveness, assurance, dan empathy terhadap kepuasan mahasiswa.

Hasil dari penelitian ini telah sesuai dengan hipotesis dan hasil penelitian Pakpahan (2004), Winarto et al. (2012), Effiyaldi (2008). Hasil penelitian tersebut menemukan bahwa secara umum mahasiswa cenderung puas terhadap layanan akademik (tutorial tatap muka) dan non-akademik (administrasi dan informasi). Selanjutnya hasil dari penelitian ini juga telah didukung oleh temuan dari penelitian Srinadi dan Desak (2008) yang menyatakan bahwa tingkat kualitas layanan akademik dengan indikator 1) tangible, 2) reliability, 3) responsiveness, 4) assurance, dan 5) empathy akan dapat mempengaruhi terhadap tingkat kepuasan mahasiswa.

Sementara itu, di bawah ini akan dijelaskan masing-masing (secara parsial) dimensi kualitas layanan akademik berdasarkan dari urutan dimensi yang tidak berpengaruh secara signifikan sampai yang berpengaruh secara signifikan terhadap kepuasan mahasiswa. Penjelasan dimensi kualitas layanan akademik tersebut antara lain:

Variabel kualitas layanan akademik pada Indikator reliability, hipotesis awal peneliti menduga bahwa varabel inilah yang paling berpengaruh terhadap kepuasan mahasiswa, namun dari hasil penelitian didapat bahwa reliability tidak berpengaruh secara signifikan terhadap kepuasan mahasiswa. Hal ini dapat dilihat pada hasil nilai 0,062 > a $(0,05)$. Variabel kualitas layanan akademik pada indikator responsiveness. Dari hasil penelitian ini didapat bahwa indikator responsiveness tidak berpengaruh secara signifikan terhadap kepuasan mahasiswa. Hal ini dibuktikan oleh nilai 0,576>a $(0,05)$.

Variabel kualitas layanan akademik pada indikator Assurance. Hasil temuan ini didapat bahwa variabel assurance tidak berpengaruh secara signifikan terhadap kepuasan mahasiswa. Hal ini dibuktikan oleh nilai $0,550>$ a $(0,05)$, artinya variabel kualitas layanan akademik pada indikator Assurance secara parsial tidak ada pengaruh yang signifikan terhadap kepuasan mahasiswa. Kondisi ini bisa saja mencerminkan bahwa responden tidak terlalu tertarik atau memperhatikan kualitas pelayanan dari item ini. 
Variabel kualitas layanan akademik pada indikator tangibles. Dari hasil penelitian didapat bahwa variabel dimensi tangibles berpengaruh secara signifikan terhadap kepuasan. Hal ini dapat dilihat pada hasil nilai $0,040<a(0,05)$. Variabel kualitas layanan akademik pada indikator empathy. Dari hasil penelitian didapat bahwa variabel dimensi emphaty berpengaruh secara signifikan terhadap kepuasan mahasiswa. Hal ini dapat dilihat dari hasil penelitian yang mendapatkan nilai $0,036<a(0,05)$.

Temuan-temuan dalam penelitian ini terbukti mendukung teori Parasuraman dan Zeithaml (1990) di mana tolak ukur kualitas pelayanan dapat diukur oleh 10 sub variabel (dimensi) yaitu: tangible (berwujud), reliability (keandalan), responsiveness (kerosponsifan), competence (pengetahuan dan ketrampilan), cortesy (perilaku), credibility (kejujuran), security (keamanan), acces (kemudahan hubungan), communicatiaons (komunikasi), dan understanding. Kesepuluh variabel itu pada dasarnya sama dengan lima variabel yang digunakan sebagai dasar dalam penelitian ini, yakni: tangible, reliability, responsiveness, assurance, dan empathy.

\section{KESIMPULAN}

Berdasarkan hasil dan pembahasan, dapat diambil kesimpulan sebagai berikut. Secara parsial indikator dimensi keterandalan (reliability), responsiveness dan assurance tidak berpengaruh secara signifikan terhadap kepuasan mahasiswa. Hal ini disebabkan Program Pascasarjana Universitas Terbuka pada Unit Program Belajar Jarak Jauh (UPBJJ) Mataram belum bisa melaksanakan pelayanan seperti yang diharapkan oleh mahasiswa. Sementara itu, indikator tangibles dan empathy secara parsial memiliki pengaruh yang signifikan terhadap kepuasan mahasiswa. Dari ke lima indikator tersebut dapat dilihat dimensi emphaty memiliki pengaruh yang paling dominan terhadap kepuasan mahasiswa. Program Pascasarjana Universitas Terbuka pada Unit Program Belajar Jarak Jauh (UPBJJ) Mataram sebaiknya terus meningkatkan pelayanan mahasiswa dengan terus meningkatkan kualitas akademik, sehingga berdampak pada kenyamanan mahasiswa. Selain itu juga perlu melakukan peningkatan profesionalisme dan pengetahuan pegawai serta peningkatan fasilitas penunjang. Hal ini diperlukan untuk dapat meningkatkan kredibitas perguruan tinggi yang bersangkutan.

Secara simultan kualitas layanan akademik yang terdiri dari tangible, reliability, responsiveness, assurance, dan empathy mempunyai pengaruh signifikan yang sangat tinggi, yang artinya semakin tinggi kualitas pelayanan maka semakin tinggi pula tingkat kepuasan mahasiswa Program Pascasarjana Universitas Terbuka pada Unit Program Belajar Jarak Jauh (UPBJJ) Mataram. Berkaitan dengan hal tersebut disarankan agar Program Pascasarjana Universitas Terbuka pada Unit Program Belajar Jarak Jauh (UPBJJ) Mataram lebih meningkatkan kualitas pelayanan, terutama lebih memberikan perhatian kepada mahasiswa, sehingga hal ini dapat lebih meningkatkan kepuasan mahasiswa dan dapat membangun kerja sama dalam jangka waktu yang lebih panjang.

\section{REFERENSI}

Effiyaldi. (2008). Analisis kualitas pelayanan terhadap kepuasan mahasiswa pada perpustakaan STIKOM Dinamika Bangsa. Jurnal Media Akademik, vol 2(1): 68-76.

Handayani, R, Yermias T. K., \& Ratminto. (2003). Analisis kepuasan pemakai terhadap pelayanan perpustakaan nasional provinsi daerah istimewa Yogyakarta. Sosiosains, vol 17(2), April 2003. Pasca Sarjana Fisipol UGM, Yogyakarta.

Holtzclaw, L.R. (1986). Human development and the distance learner. I.C.D.E Bulletin, vol. 10, 17-19. 
Irawan, H. (2002). 10 Prinsip kepuasan pelanggan. Penerbit PT. Elex Media Komputindo Gramedia, Jakarta.

Kartono, K. (1987). Pemimpin dan kepemimpinan:apakah kepemimpinan itu abnormal. Penerbit Rajawwali, Jakarta.

Keputusan Menteri PAN Nomor: 63/KEP/M.PAN/7/2003 tentang Pedoman Umum Penyelenggaraan Pelayanan Publik.

Kotler, P.( 2000). Marketing management $9^{\text {th }}$ edition. New Jersey. Prentice Hall International. Inc.

Ndendo, Tanggu, Roland. (2007). Analisis kepuasan mahasiswa terhadap pelayanan PSMA on-line Universitas Gunadharma. Proceeding Pesat Universitas Gunadharma. Jakarta.

Pakpahan, Sondang Purnamasari. (2004). Persepsi mahasiswa UPBJJ-UT Medan tentang pelayanan akademik dan non-akademik yang diberikan oleh UPBJJ-UT Medan. Jurnal pendidikan terbuka dan jarak jauh, vol 5(1): 47-58.

Semiawan, C. R. (1998). Pendidikan tinggi peningkatan kemampuan manusia sepanjang hayat seoptimal mungkin. Direktorat Jenderal Pendidikan Tinggi, Jakarta.

Srinadi, I Gusti Ayu Made \& Desak Putu Eka Nilakusmawati. (2008). Faktor-faktor penentu kepuasan mahasiswa terhadap pelayanan fakultas sebagai lembaga pendidikan (studi kasus FMIPA Universitas Udayana). Cakrawala pendidikan Tahun XXVII No 3, Denpasar.

Sudarwan, D. (1995). Pendidikan Media Komunikasi. Penerbit Bumi Aksara, Jakarta.

Tjiptono, F. (1998). Manajemen jasa. Edisi kedua. Penerbit Andi Offset, Yogyakarta.

William, J. \& William, M. (1987). Student operated network for diatance learners. I.C.D.E Bulletin, vol. 13, 51-64.

Zeithaml, Parasuraman \& Berry. (1990). Delivering quality service: Balancing customer perceptions and expectations, The Free Press, USA. 